Religious Studies 37, 357-358 (C) 2001 Cambridge University Press

DOI: $10.1017 /$ S0034412501005716 Printed in the United Kingdom

\title{
Swinburne and Plantinga on internal rationality
}

\begin{abstract}
Note: This brief discussion arises out of Richard Swinburne's critical notice of Alvin Plantinga's Warranted Christian Belief (New York NY: Oxford University Press, 2000) and Plantinga's reply in Religious Studies, 37 (2001), 203-214, 215-222.
\end{abstract}

\section{RICHARD SWINBURNE}

Oriel College, Oxford University, Oxford, OX1 4EW

Plantinga defines S's belief as 'privately rational if and only if it is probable on S's evidence', and 'publicly rational if and only if it is probable with respect to public evidence', and he claims that 'it is an immediate consequence of these definitions that all my basic beliefs are privately rational'. I made it explicitly clear in my review that on my account of a person's evidence (quoted and used by Plantinga) as 'the content of his basic beliefs (weighted by his degree of confidence in them)', that is not the case. I emphasize 'weighted by his degree of confidence in them'. I wrote explicitly: 'for more or less any belief, however convinced you are of it initially, other evidence of which you are equally convinced could rend it overall improbable'. Put technically, in probabilistic terms, basic beliefs come to us with different degrees of prior probability varying with our degree of confidence in them, but a belief with a high prior probability can in the light of other beliefs of our current set have a lower posterior probability. If you continue to hold on to a basic belief when its probability on the total evidence is below half, that belief is not privately rational.

\section{ALVIN PLANTINGA}

Department of Philosophy, University of Notre Dame, Notre Dame, IN 46556

I took it that the definitions Swinburne quotes imply that all of a person's basic beliefs are (privately) rational; Swinburne demurs. It still seems to me that these definitions have this consequence. Let me briefly explain why. According to Swinburne, a person's evidence consists of his basic beliefs, weighted by his confidence in them. So presumably we are to think of S's evidence as the set of the beliefs he takes in the basic way, together with a sort of index indicating, for each 
of those beliefs, his degree of confidence in that belief. Now it is clear, first, that different basic beliefs can be held with different degrees of confidence. I believe $2+1=3$ more firmly than there are presently some large trees in my backyard, and I believe that second proposition more firmly than I played bridge last night. Nevertheless, I believe all three propositions; I don't just believe them probably. So, the set of my basic beliefs contains propositions, all of which I believe. Further, a belief of mine is 'rendered (evidentially) probable by [my] evidence', I take it, just if it is probable with respect to the set of my basic beliefs. But of course probability of 1 with respect to that set; the degree of confidence with which I hold those beliefs does not seem to be relevant. Hence my conclusion that on these definitions all of my basic beliefs are rational.

Swinburne points out that some of my basic beliefs may be improbable with respect to the rest of my basic beliefs; these beliefs, then, might be thought irrational, at least if they are not held as firmly as those with respect to which they are improbable. But this seems to me an uninteresting sense of 'irrational'. Many of my basic beliefs are improbable with respect to my other basic beliefs; they are none the worse for that. I now remember, as it seems to me, that in the second bridge hand last night I was dealt three aces, three jacks, and three deuces. This is unlikely on the rest of my basic beliefs. It is, nonetheless, not irrational in any useful sense; memory is an important and independent source of rational belief, a source such that its deliverances do not necessarily depend, for warrant or rationality, on their probability with respect to other basic beliefs. I believe the same goes for some of my Christian beliefs. They may be improbable with respect to other beliefs, basic or otherwise, that I hold; but that need be nothing whatever against them. 